\title{
EXCITATION AND DYNAMIC RESPONSES OF JACKET STRUCTURES IN REGULAR WAVES FOR OFFSHORE INSTALLATION
}

\author{
Mario Welzel ${ }^{1}$, Tobias Kreklow ${ }^{1}$, Torsten Schlurmann ${ }^{1}$, Arndt Hildebrandt ${ }^{1}$
}

\begin{abstract}
The world's energy supply needs to scope two aims: Securing an ongoing growth in energy demand while gradually shifting to exploitation of renewable energy resources. Since onshore and near shore areas to harvest energy from wind are running short, the focus is laid on concepts for deep water regions ranging from 30 up to $50 \mathrm{~m}$ with $\geq 6 \mathrm{MW}$. The presented work is a part of the research project HyConCast which progresses the development of a novel, hybrid support structure for offshore wind turbines. Thereby the concept addresses to develop and deploy hybrid offshore wind farm support structures which are based on the advantages of combined ductile iron casting knots and precast concrete pipes. The overall objective of the project is to assess the feasibility and general applicability under design load cases stemming from environmental, eco-logical and economical dimensions. With respect to the distinctly higher total weight of the hybrid structure compared to common steal structures, the results of its so far not understood excitation and dynamic motion response in regular waves during floating installation are researched and discussed in the following article.
\end{abstract}

Keywords: offshore installation; physical model test; motion response

\section{INTRODUCTION}

The usage of wind energy is one of the fastest growing renewable energy forms over the last years. As a result of the IPCC report, $77 \%$ of the worlds energy supply could come from renewable energy sources by 2050 (IPCC Special Report SSREN, 2011). Offshore wind turbines within coastal areas provide a major energy contribution and upcoming projects seek to open up new available space at larger water depths (Sun et al. 2012). This triggers the initiation of R\&D on novel and innovative structures with special attention for construction, installation, operation and maintenance. The presented work is a part of the research project HyConCast (Funding Code FKZ 0325651A) funded by the German government and progresses the development of a novel, hybrid support structure for offshore wind turbines. Thereby the structural concept is based on the advantages of combined ductile iron casting knots and precast concrete pipes (see Fig. 3). The hybrid support structure is developed to be installed in deep water regions ranging from 30 up to $50 \mathrm{~m}$ with $\geq 6 \mathrm{MW}$. The overall objective of the project is to assess the feasibility and applicability under design load cases stemming from environmental, ecological and economical dimensions. From the engineering point of view, one of the most demanding tasks during the transport and installation of a support structure is the final offshore installation. Compared to common steal structures, the novel hybrid support structure has a distinctly higher total weight. The float-over method is most often applied due to its economic benefits over lifting procedures, especially when lift capacities exceed available crane vessels (Chakrabarti, 2005). Self-floating structures are for example launched from a barge. Through ballast shifting, the up-ending is initialized as the second phase. Finally the set down is executed via controlled ballasting of the buoyancy tanks. Honarvar et al. (2008) investigated the launch operation of jackets from a barge. They compared physical modelling results with numerical simulations of a jacket launching. Especially when the structure reaches the vertical position, the floating body is very sensitive to tipping momentum exerted from waves and currents. This applies in particular to the floating lowering process of the foundation right before the touchdown on the sea bed (see Fig. 1).

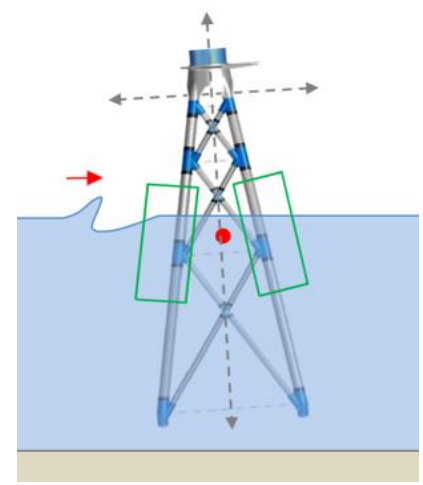

Figure 1. Positioning and lowering of floating jacket including buoyancy tanks (illustrated in green) exposed to waves

\footnotetext{
${ }^{1}$ Ludwig-Franzius-Institute for Hydraulic, Estuarine and Coastal Engineering Leibniz Universität Hannover Nienburger Str. 4 Hanover, Lower Saxony, Germany
} 
Previous studies encompass Nallayarasu et al. (2015), Bunnik and Buchner (2004) and Cozijn et al. (2005) made experimental and numerical investigations of the hydrodynamic response behaviour of structures under regular waves. They also showed how the response behaviour can be reduced with a decreasing water plane area resulting in different shapes of the buoyancy body in the water-plane area. Similar to a spar buoy the floating jacket is in its vertical position and has a low centre of gravity. Due to the mass distribution and the resulting momentum of inertia as well as the metacentric height of the here introduced hybrid support structure this results in difficult conditions for the offshore installation, and therefore has to be analysed thoroughly before moving into operations.

\section{Objectives}

This paper investigates and discusses the sensitivity of the structures excitation and response to regular waves for wave directions of $0^{\circ}$ and $45^{\circ}$ heading during the critical stage prior to touchdown on the seafloor. Furthermore, the response behaviour of the floating structure is investigated. For a safe floating installation, the jacket has to adopt a stable position as well as a minimum metacentric height (Noble, Denton and Associates, 2013). The motion response during lowering and positioning of the support structure is critical for the entire floating installation. This enables a first assessment of the installation process in the context of narrow time windows for a complete offshore wind farm.

\section{METHOLOGY}

\section{Experimental Setup}

Physical model tests with a scale of $\lambda=45$ were performed in the wave flume of the Ludwig-FranziusInstitute (see Figure 2). Resulting drift loads on the structure are measured with U9C force transducers from HBM. The model is kept in position with a soft mooring system to determine the wave-structure responses. The force transducers are integral part of the soft mooring lines system. The soft mooring lines are additionally composed of springs, joints and a thin wire as described in Kurian et al. (2013). Structure's motions are measured with an optical infrared tracking system with six degrees of freedom and a deviation of $0.1 \mathrm{~mm}$. To avoid reflections of the infrared light and therefor measurement uncertainties, active markers where used for the conducted experiments. Ultrasonic wave gauges determined the incident and transmitted and reflected wave height. Therefor the wave gauges where placed in front, behind and in the axis of the physical model according to Mansard and Funke (1980) in order to disintegrate incident, reflected and transmitted wave trains following a complex wave-structure interaction.

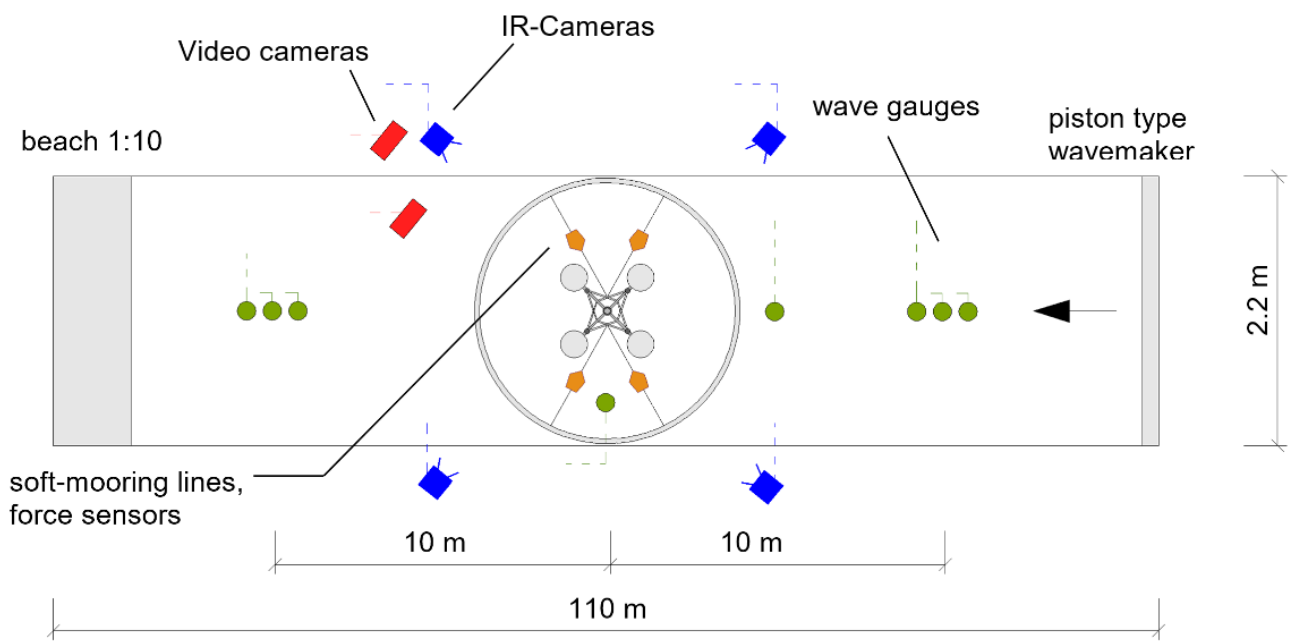

Figure 2. Experimental setup and measurement equipment, heading $0^{\circ}$ 


\section{Physical Model}

The physical model (see Figure 3.) is scaled according to FROUDE scaling and has the following parameters, see Tab.1. Analysis of different buoyancy tank constructions led to a mass-buoyancy ratio of $7.11 \mathrm{~m}^{3} / \mathrm{t}$. To create a sufficient freeboard height in order to avoid overtopping of the tanks resulting in a reduction of the metacentric height due to free surface effect, a reserve buoyancy of $30 \%$ is taken into account. This operational strategy assures the survivability on all planned investigations and practically avoids capsizing of the entire floating structure. Furthermore, this arrangement is chosen to generate the highest possible $\overline{\mathrm{BM}}$ through maximizing the second moment of area of the water-plane. The influence of the stability $\overline{\mathrm{GM}}$ in terms of further geometric buoyancy distribution in

$$
T=\frac{2 \pi k}{\sqrt{g \overline{G M}}}
$$

needs to be investigated in additional test runs. The dimensions and parameter of the buoyancy tanks are shown in Tab.2.

\begin{tabular}{|l|r|l|r|l|}
\hline \multicolumn{5}{|c|}{ Table 1. Model parameters according to } \\
FROUDE scaling \\
\hline$\lambda=45$ & \multicolumn{1}{|c|}{ Full - Scale } & \multicolumn{2}{|c|}{ Model - Scale } \\
\hline $\mathrm{h}$ & 74.00 & $\mathrm{~m}$ & 1.64 & $\mathrm{~m}$ \\
$\mathrm{~m}$ & 3665 & $\mathrm{t}$ & 40.2 & $\mathrm{t}$ \\
$\rho_{\text {water }}$ & 1025 & $\mathrm{~kg} / \mathrm{m}^{3}$ & 998.8 & $\mathrm{~kg} / \mathrm{m}^{3}$ \\
$\overline{\mathrm{V}}_{\text {req }}$ & 3575.6 & $\mathrm{~m}^{3}$ & 0.04 & $\mathrm{~m}^{3}$ \\
$\overline{\mathrm{V}}_{\mathrm{T}=40 \mathrm{~m}}$ & 632.2 & $\mathrm{~m}^{3}$ & 0.0069 & $\mathrm{~m}^{3}$ \\
\hline
\end{tabular}

\begin{tabular}{|l|r|l|r|l|}
\hline \multicolumn{5}{|c|}{$\begin{array}{c}\text { Table 2. Buoyancy Tank parameters } \\
\text { according to FROUDE scaling }\end{array}$} \\
\hline$\lambda=45$ & \multicolumn{1}{|c|}{ Full - Scale } & \multicolumn{2}{|c|}{ Model - Scale } \\
\hline $\mathrm{m}$ & 199.0 & $\mathrm{t}$ & 2.2 & $\mathrm{~kg}$ \\
$\overline{\mathrm{V}}$ & 1415.8 & $\mathrm{~m}^{3}$ & 0.0155 & $\mathrm{~m}^{3}$ \\
$\mathrm{~d}$ & 9.90 & $\mathrm{~m}$ & 0.220 & $\mathrm{~m}$ \\
$\mathrm{~h}$ & 19.10 & $\mathrm{~m}$ & 0.424 & $\mathrm{~m}$ \\
& & & & \\
\hline
\end{tabular}
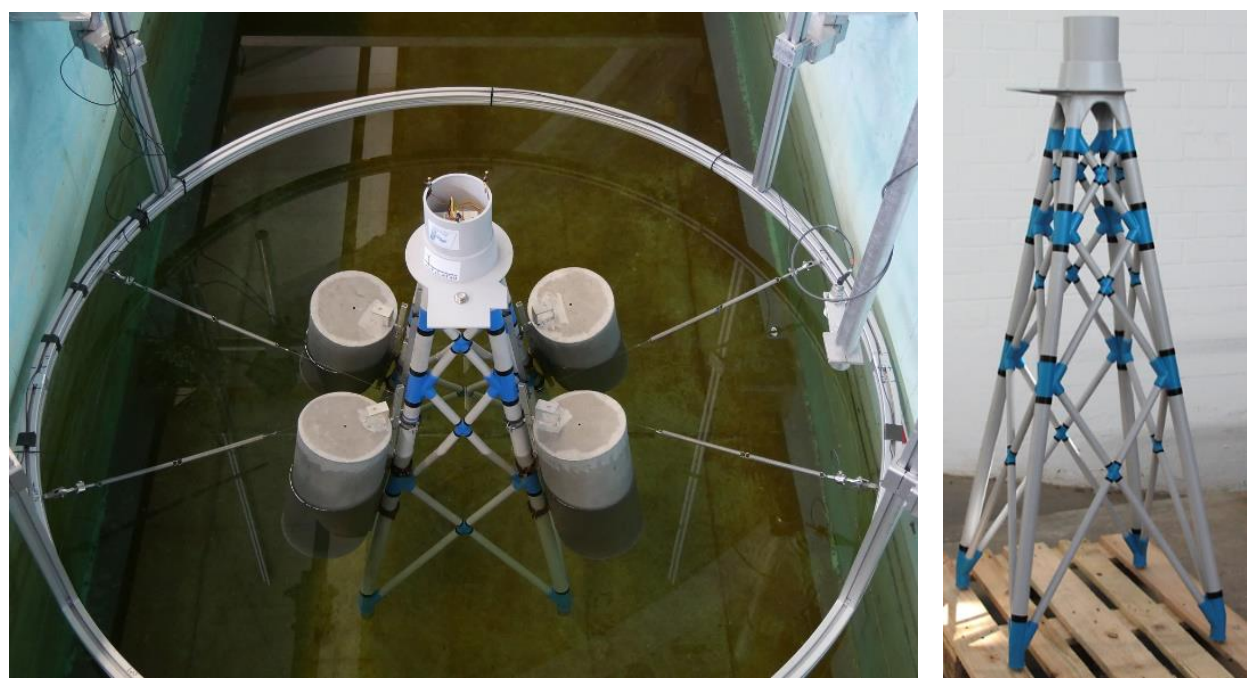

Figure 3. Buoyancy tanks installed $45^{\circ}$, structure heading $0^{\circ}$ (left), Structure without buoyancy tanks (right)

An initial test run was conducted in calm sea states to follow a structural decay analysis. The natural frequencies of the model where measured. Especially, the fundamental modes of the natural frequency in the dimensions of heave as well as in pitch and roll are important for the presented and discussed stability analysis. The natural frequency in heave was measured with $1 / 1.25 \mathrm{~s}$ and the natural frequency in pitch and roll with $1 / 2.25 \mathrm{~s}$.

To determine the influence of the soft mooring system on the structure oscillations decay tests with and without mooring lines where compared with each other. The pitch movements of the mooring line decay test had a deviation of about $1.38 \%$ to the same decay test without mooring lines. Overall the influence of stiffness of the mooring regarding the restriction of motion was assessed as $\sim 1-3 \%$. 


\section{Physical Model Tests}

To define the wave parameters, field data from the German Research Platform FINO1 where taken into account. The data is available through the Federal Maritime and Hydrographic Agency (BSH) on request. The platform located in the western part of the North Sea $45 \mathrm{~km}$ off Borkum is one of two in the German North Sea and has a water depth of 30m. The platform went into operation in 2003 and is one of the most suited sources of credible and reliable research platforms for providing $>10$-year offshore wave record. A statistical analysis of the recorded sea state show that $\mathrm{H}_{\mathrm{S}}=1 \mathrm{~m}-3 \mathrm{~m}$ significant wave heights with $\mathrm{T}_{\mathrm{p}}$ $=6 \mathrm{~s}-8 \mathrm{~s}$ peak periods are the most common sea states (see Tab.3) in a 10-year time series.

Regarding the deployment of a floating offshore structure, oscillations should be limited. Therefore, the maximum wave height was chosen to $3.5 \mathrm{~m}$, the minimum wave height was chosen to $1.5 \mathrm{~m}$ due to physical modelling limitations with regard to sufficient wave contour. This sea state range equals a probability of about $\sim 54 \%$. Due to limitations of the wave maker in the hydraulic facility, the performance of the floating structure was assessed in between $6 \mathrm{~s}<\mathrm{T}<14 \mathrm{~s}$., see Tab.3.

\begin{tabular}{|c|c|c|c|c|c|c|c|c|c|c|c|c|c|c|c|}
\hline \multicolumn{10}{|c|}{ Table 3. Relative frequency [\%] of $H_{S}$ and T derived from data base of FINO 1 } \\
for a 10-year period (01.01.2004 until 31.12.2013) \\
\hline $\mathrm{H}_{\mathrm{S}} \mathrm{T}_{\mathrm{P}}$ & $<2$ & 3 & 4 & 5 & 6 & 7 & 8 & 9 & 10 & 11 & 12 & 13 & 14 & $\geq 15$ & Sum \\
\hline 0.25 & 0.02 & 0.06 & 0.13 & 0.16 & 0.08 & 0.04 & 0.03 & 0.03 & 0.13 & 0.02 & 0.06 & 0.04 & 0.01 & 0.01 & 0.82 \\
\hline 0.50 & 0.02 & 0.91 & 1.98 & 1.58 & 1.05 & 0.51 & 0.49 & 0.33 & 0.64 & 0.22 & 0.46 & 0.28 & 0.24 & 0.40 & 9.11 \\
\hline 0.75 & & 0.37 & 3.03 & 2.72 & 2.25 & 1.30 & 0.82 & 0.44 & 0.75 & 0.22 & 0.46 & 0.33 & 0.20 & 0.64 & 13.53 \\
\hline 1.00 & & 0.01 & 1.95 & 4.38 & 2.32 & 1.94 & 1.30 & 0.36 & 0.66 & 0.27 & 0.51 & 0.24 & 0.13 & 0.45 & 14.52 \\
\hline 2.00 & & & 0.64 & 6.54 & 10.05 & 8.24 & 7.85 & 2.59 & 1.55 & 0.32 & 0.59 & 0.33 & 0.18 & 0.42 & 39.30 \\
\hline 3.00 & & & & 0.04 & 0.83 & 3.32 & 6.00 & 3.35 & 1.78 & 0.23 & 0.24 & 0.08 & 0.03 & 0.12 & 16.02 \\
\hline 4.00 & & & & & & 0.12 & 1.05 & 1.43 & 1.48 & 0.30 & 0.27 & 0.07 & 0.01 & 0.01 & 4.74 \\
\hline 5.00 & & & & & & & 0.02 & 0.19 & 0.55 & 0.19 & 0.20 & 0.08 & 0.02 & 0.02 & 1.27 \\
\hline 6.00 & & & & & & & & 0.01 & 0.10 & 0.08 & 0.15 & 0.07 & 0.01 & 0.01 & 0.43 \\
\hline 7.00 & & & & & & & & & 0.01 & 0.01 & 0.07 & 0.03 & 0.01 & 0.00 & 0.13 \\
\hline$\geq 8.00$ & & & & & & & & & & & 0.02 & 0.02 & 0.01 & 0.03 & 0.06 \\
\hline Sum & 0.04 & 1.35 & 7.73 & 15.42 & 16.58 & 15.47 & 17.56 & 8.73 & 7.65 & 1.86 & 3.03 & 1.57 & 0.85 & 2.12 & 100.00 \\
\hline
\end{tabular}

The selected wave heights of $1.5-3.5 \mathrm{~m}$ correspond to $2.22-7.78 \mathrm{~cm}$ wave heights in model scale $(\lambda=$ $45,1: \lambda)$. The wave periods of $6-14$ s correspond to $0.89-2.09$ s in model scale $\left(\lambda=45,1: \lambda^{0.5}\right)$. Physical model tests with regular waves of $0^{\circ}, 22.5^{\circ}$ and $45^{\circ}$ heading of the structure to the waves where conducted (see Figure 3 for $0^{\circ}$ ). The investigated wave heights for $22.5^{\circ}$ and $45^{\circ}$ were chosen as $4.4 \mathrm{~cm}$ and $5.5 \mathrm{~cm}$.

\section{RESULTS}

\section{Time signals}

In this study, uni-directional regular waves with different wave heights and wave periods where generated (see Tab.3) to investigate the excitations and dynamic response of the model for different sea states. The generated waves triggered various degrees of freedom. For the Response Amplitude Operator analysis, an undisturbed time signal window needs to be selected. Thereby transient effects like the increasing wave height at the start or end of the measurement, reflections or delayed oscillations of the structure should be considered. The floating body needs to reach a stationary oscillation. Thereby it is important to study the incoming waves, but also the motion response itself. Since the motion, itself as well as the time required to reach a oscillating response motion varied significant throughout the tests, a manually performed evaluation formed the basis for the up following frequency analysis.

As an example, in Figure 4 the selected time signal windows for tests with different wave periods are presented as the two most critical sea conditions in comparison to each other. The wave periods of $1.34 \mathrm{~s}$ produced the highest oscillations in heave. The horizontal dashed lines display the incident wave height for orientation. 

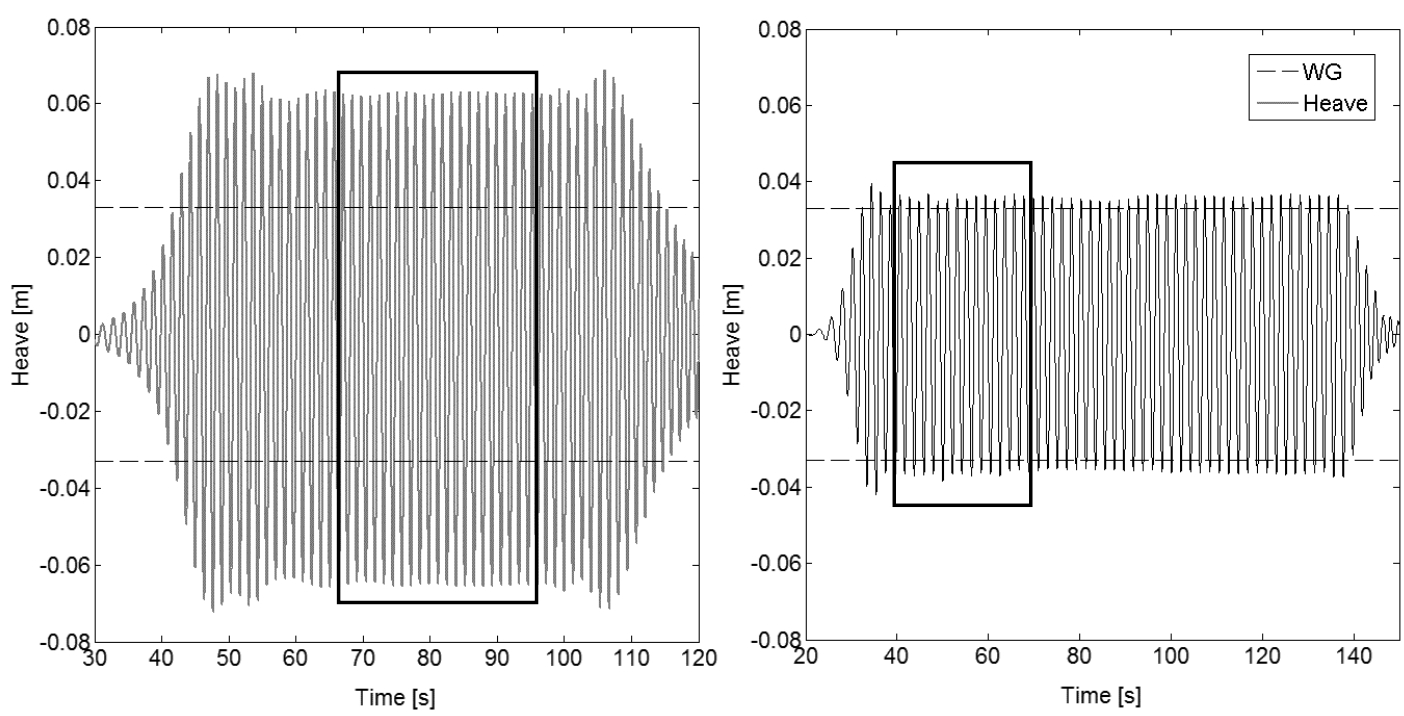

Figure 4. Heave motion for a wave period of $1.34 \mathrm{~s}$ and a wave height of $6.6 \mathrm{~cm}$ (left); heave motion for a wave period of $2.09 \mathrm{~s}$ and a wave height of $6.6 \mathrm{~cm}$ (right); with $0^{\circ}$ wave direction

The wave period of 2.09s produced the highest pitch motion. Again, the diagrams of Figure 5 compare the pitch motion of the most critical wave periods of $1.34 \mathrm{~s}$ and $2.09 \mathrm{~s}$. The pitch motion for the test close to the natural frequency of pitch of the structure (see Figure 5, right) is six times higher than the pitch angle of the test generating the highest heave motion (see Figure 5, left).
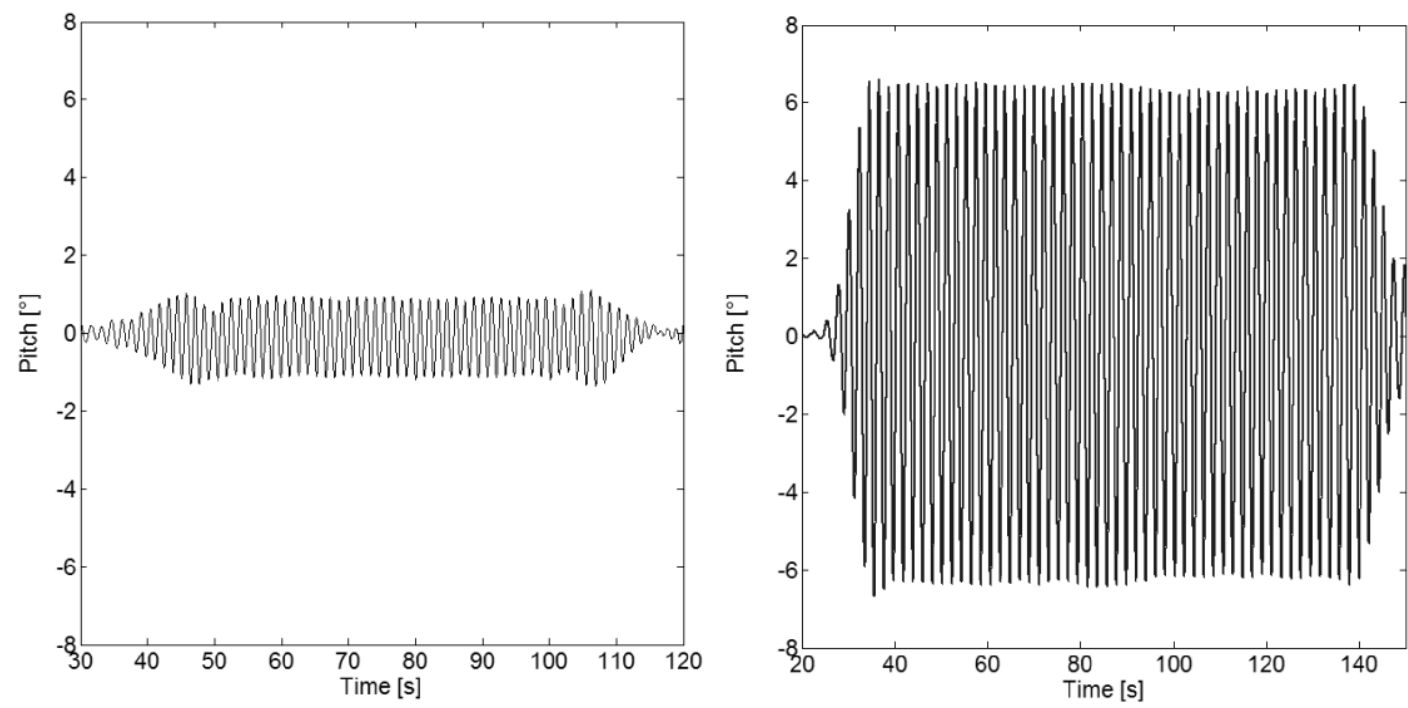

Figure 5. Pitch motion for a wave period of $1.34 \mathrm{~s}$ and a wave height of $6.6 \mathrm{~cm}$ (left); Pitch motion for a wave period of 2.09s and a wave height of $6.6 \mathrm{~cm}$ (right); with $0^{\circ}$ wave direction

Figure 6 shows the measured forces of the soft mooring lines one and two in direction of the incoming waves. Figures 4, 5 and 6 show time signals for a structure heading of $0^{\circ}$. Forces in wave direction, as shown in Figure 6, are signed positively. The line forces at the front of the structure towards the incoming waves show an amplitude of approximately $0.25 \mathrm{~N}$ for the wave period of $1.34 \mathrm{~s}$. In the left time signal of Figure 6 a drift force of approximately $+0.32 \mathrm{~N}$ is observed. The comparable shorter waves with a period of $1.34 \mathrm{~s}$ induce a constant periodic force which leads to an overall hydrodynamic compact behaviour of the structure. The increasing wave height at the start of each measurement was observed in the wave gauge signals as well as in the response behaviour. This leads to the observed force peak of the outlier in Figure 6, left. The up following drift offset, is followed by periodic forces. The increasing wave length for waves up to the investigated period of $2.09 \mathrm{~s}$ let the structure follow the wave contour. This results in 
a uniform motion besides the initial small drift due to the super elevation of the wave generation at the beginning of the test run. The drift force has the maximum at the wave period of $0.90 \mathrm{~s}$ and is decreasing to longer wave periods. However, the force amplitude is increasing with higher wave periods, see Figure 6 (right).
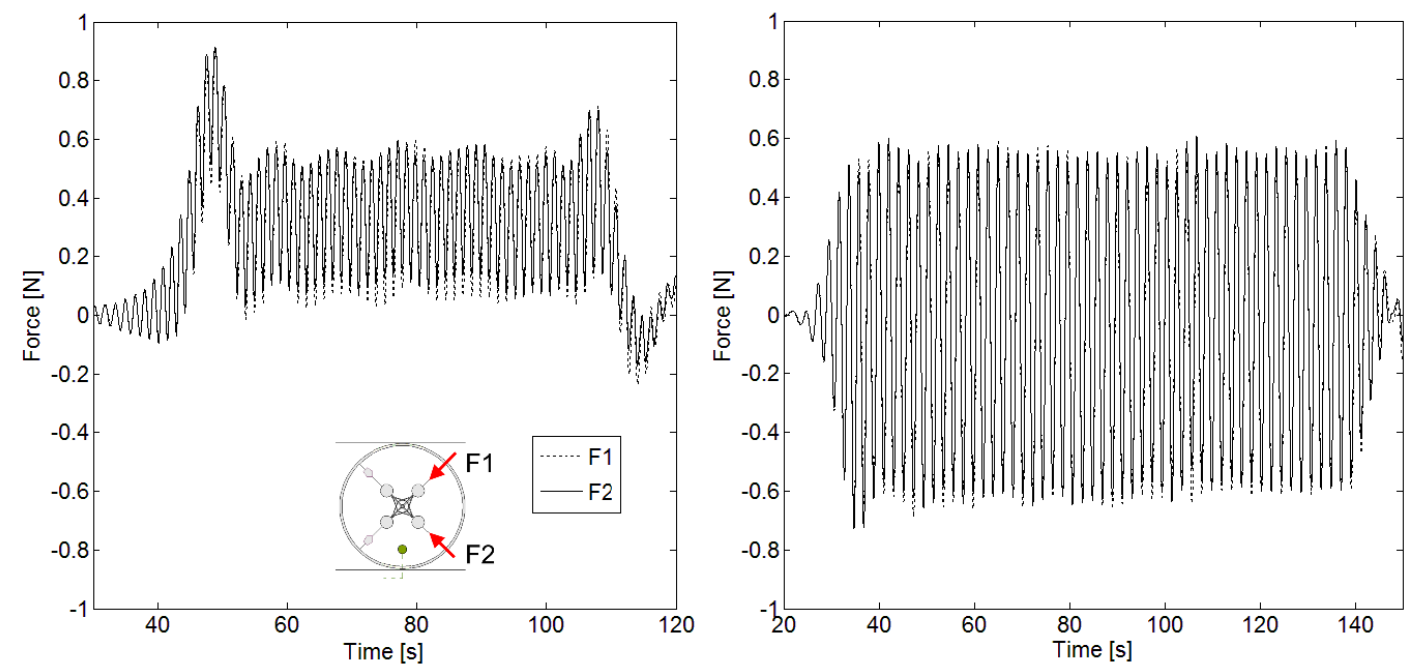

Figure 6. Force transducer 1 and 2 for a wave period of $1.34 \mathrm{~s}$ and a wave height of $6.6 \mathrm{~cm}$ (left); Force transducer 1 and 2 for a wave period of $2.09 \mathrm{~s}$ and a wave height of $6.6 \mathrm{~cm}$ (right)

Because of the mass distribution of the investigated structure (overhanging transition piece), the centre of gravity shows slightly in the upper left direction (see also Figure 1). Therefore, the floating structure in $45^{\circ}$ heading is forced to move in an ellipsoid way, see Figure 7. Due to this motion pattern the degrees of freedom of interest (referred to the fix orientation of the wave flume) are changing between the $0^{\circ}$ and the $45^{\circ}$ heading from heave and pitch to heave, pitch and roll.
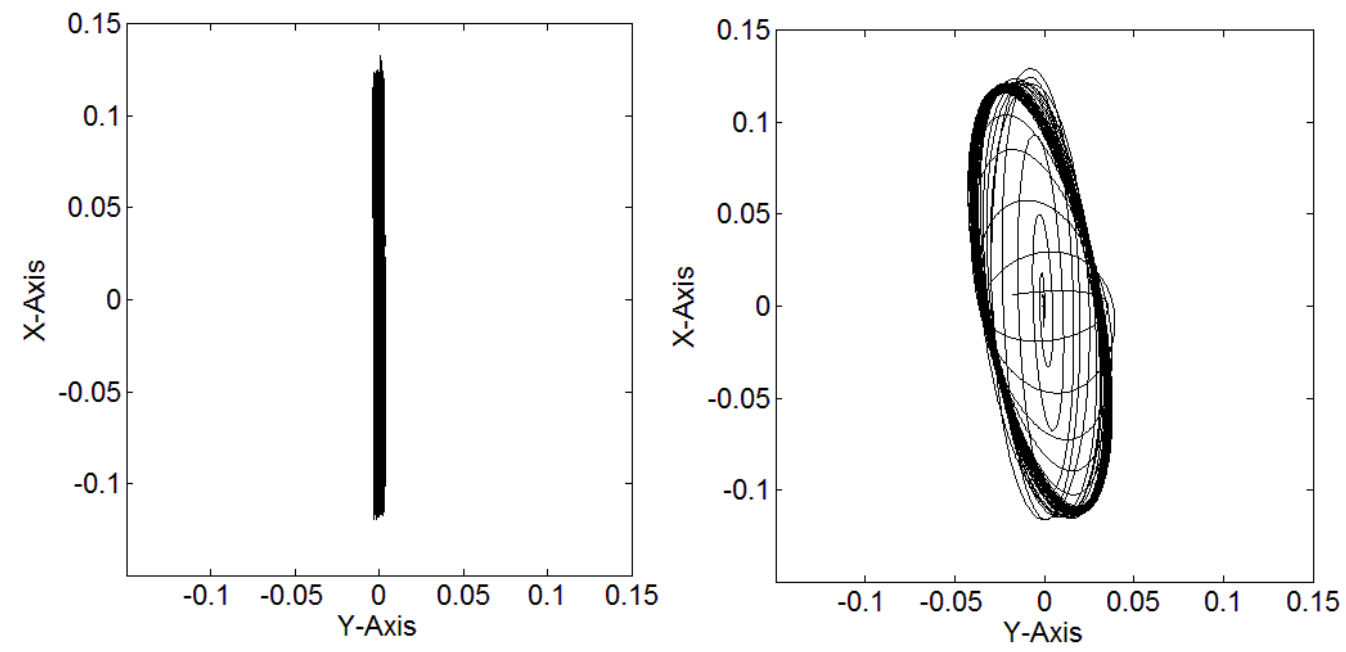

Figure 7. Phase diagrams of structure motion for wave periods of $2.09 \mathrm{~s}$ and wave height of $5.5 \mathrm{~cm}$ with $0^{\circ}$ heading wave direction (left) and $45^{\circ}$ wave direction (right)

The $45^{\circ}$ orientation shows different motions for increasing wave periods in comparison to the $0^{\circ}$ orientation. The ellipsoid motion of the structure, observed in the $45^{\circ}$ tests (see Figure 8 left), results in a same pitch motion as the $0^{\circ}$ heading with $2.09 \mathrm{~s}$ wave period and $5.5 \mathrm{~cm}$ wave height. Furthermore, the pitch motion illustrated in Figure 5, right shows nearly the same pitch motion. In contrast to the $0^{\circ}$ heading tests, a roll motion of $2.4^{\circ}$ could be observed in the $45^{\circ}$ wave direction tests (see, Figure 8 right). 
Since the $0^{\circ}$ heading tests did not force the structure in a y-axis direction, no roll motion was measured for these test cases.
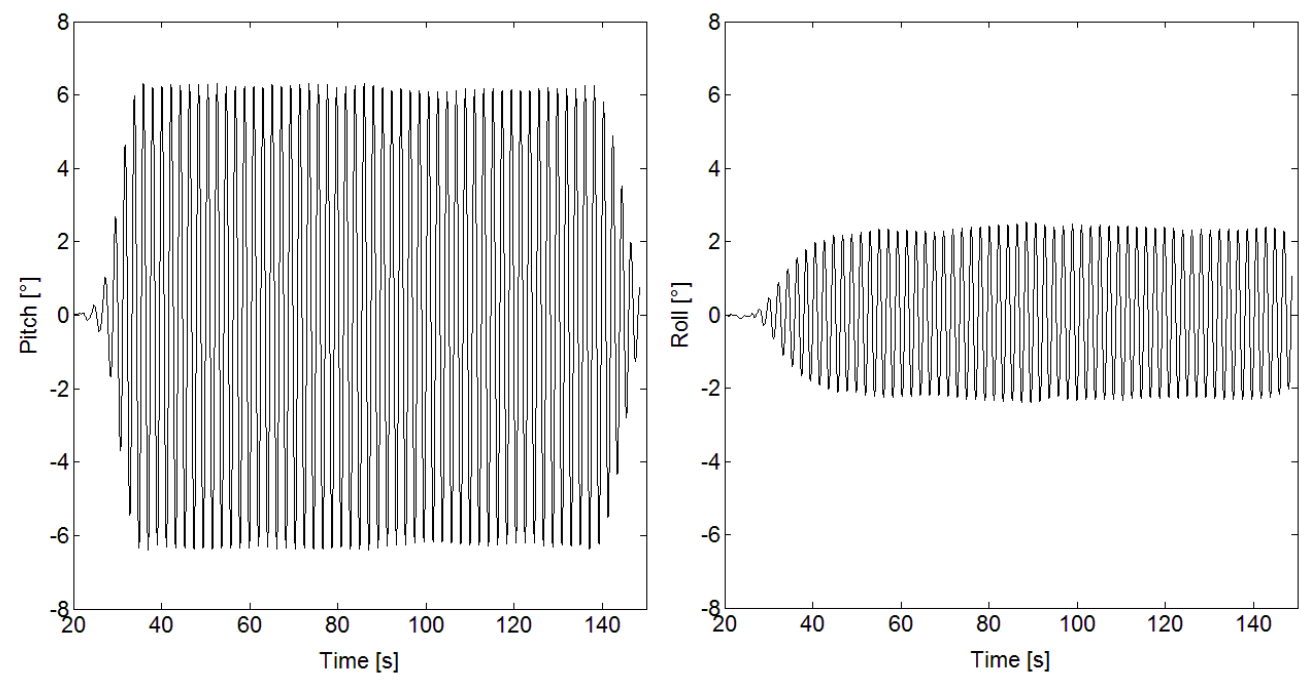

Figure 8. Pitch motion (left) and roll motion (right) for wave periods of 2.09s and wave heights of $5.5 \mathrm{~cm}$ for $45^{\circ}$ heading

\section{Response Amplitude Operators}

To gain the Response Amplitude Operators (RAO) a Fourier series analysis of each measurement was applied for the incident waves of each test as well as for the heave, pitch and roll motion response of the structure (see Figure 9). As shown in the previous chapter the time signal windows where chosen by taking various criteria into account. The measured wave heights as well as the motion response signals were filtered with adapted band pass filters. The RAOs were determined from each Fourier transformation and calculated with Eq. 2

$$
R A O=\frac{S_{R}(\omega)}{\zeta(\omega)}
$$

where $S_{R}$ is the response amplitude in heave, pitch or roll, $\zeta$ is the measured wave amplitude and $\omega$ is the angular frequency of the wave.

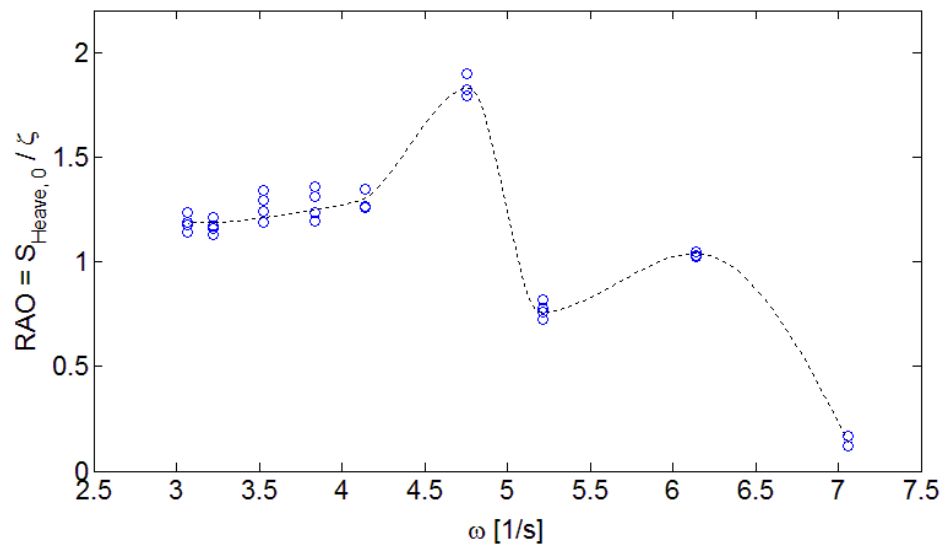

Figure 9. Heave RAO for $0^{\circ}$ heading wave direction and wave periods of $0.90 \mathrm{~s}-2.09 \mathrm{~s}$

The frequency dependent transfer function as shown in Figure 9 displays the response of the investigated structure regarding heave oscillations. The angular frequency of $\omega=3 s^{-1}$ corresponds to a wave period of $T=2.09 \mathrm{~s}(\omega=2 \pi f=2 \pi / T)$ as well as $\omega=7 \mathrm{~s}^{-1}$ with a wave period of $T=0.90 \mathrm{~s}$. As known 
from the decay analysis in heave the natural frequency of the floating structure is about $1 / 1.25 \mathrm{~s}$, which corresponds to a angular frequency of about $\omega=5 s^{-1}$. Figure 9 shows a maximum response amplitude for about $\omega=4.7 \mathrm{~s}^{-1}$, which matches almost the natural frequency of the structure. As the angular frequencys of 5.0 to 4.7 correspond to wave periods of $1.25 \mathrm{~s}$ up to $1.34 \mathrm{~s}$, heave oscillations are becoming critical for wave periods of $>8 s$ in nature.

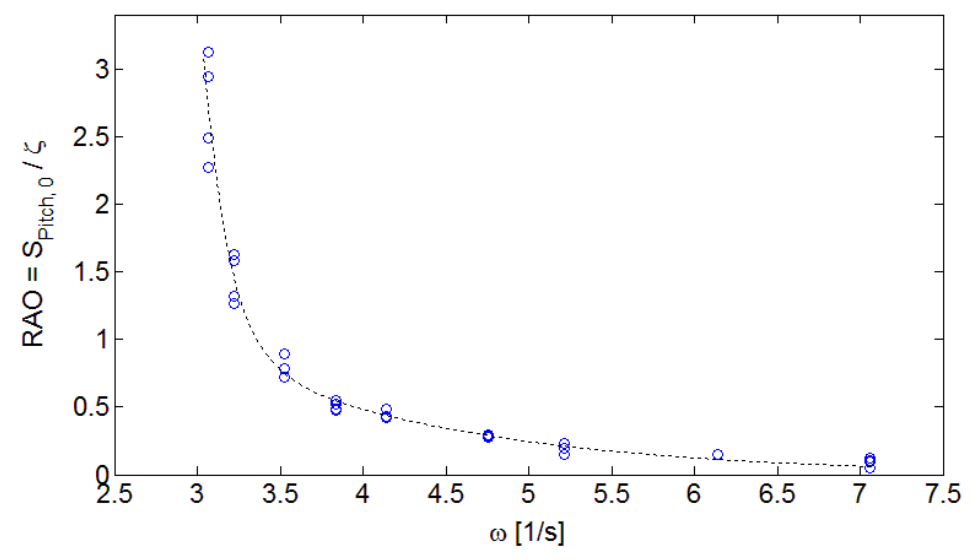

Figure 10. Pitch RAO for $0^{\circ}$ heading wave direction and wave periods of $0.90 \mathrm{~s}-2.09 \mathrm{~s}$

The transfer function shown in Figure 10 displays the response of the investigated structure regarding measured pitch oscillations. The natural frequency in pitch was found from the decay analysis and is $1 / 2.25 \mathrm{~s}$. Since the maximum simulated wave period was about $2.09 \mathrm{~s}$ the natural frequency in pitch was not completely reached in the conducted tests. Figure 10 shows that the pitch oscillations with angular frequencies of $\omega \geq 4 \mathrm{~s}^{-1}$ have a small pitch motion. Hence natural wave periods of $T \geq 10 \mathrm{~s}$ are critical for the investigated installation process.

Generally speaking, the RAOs for a heading of $45^{\circ}$ show a comparable behaviour to those of $0^{\circ}$. The local minimum at $\omega=5.3 \mathrm{~s}^{-1}$ origins in the arrangement of the buoyancy tanks (see Figure 3 ). The tests corresponding to a wave period of $1.19 \mathrm{~s}$ are the closest to the determined natural frequency of the structure. However, a pronounced damping was observed which was induced by the volume and distance between the buoyancy tanks. This is known as well for semi-submersibles or Small Water Area Twin Hull (SWATH) designs (Dhanak and Xiros, 2016). The damping is highly developed for $45^{\circ}$, leading to a motion response half as for $0^{\circ}$ in waves of $T=1.19 \mathrm{~s}$ (see Figure 11).

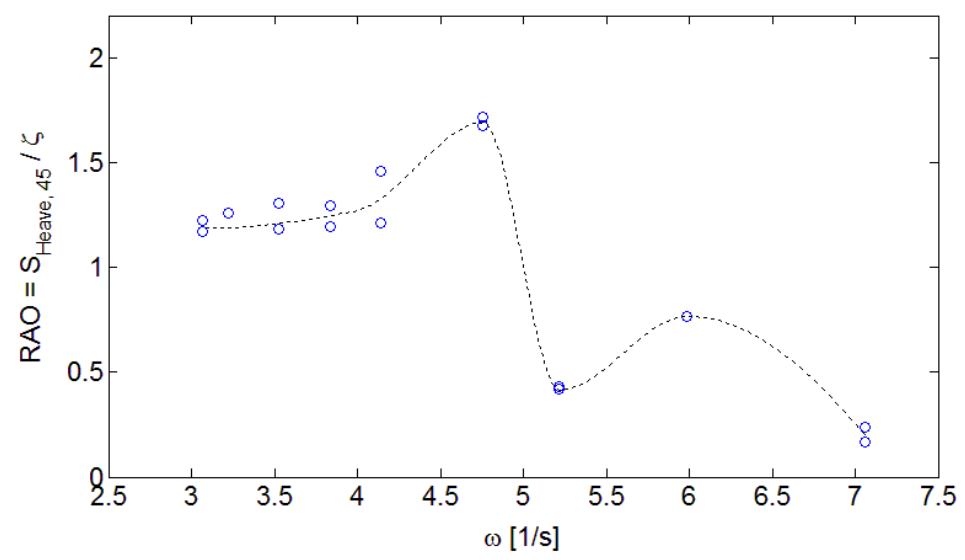

Figure 11. Heave RAO for $45^{\circ}$ heading wave direction, wave periods of $0.90 \mathrm{~s}-2.09 \mathrm{~s}$

Concerning the value spreading in $45^{\circ}$ heading for $3 s^{-1} \geq \omega>4.25 s^{-1}$ (see Figure 11) the higher values belong to wave heights of $5.5 \mathrm{~cm}$. The motion is rather uniform, however, the FFT is sensitive to 
superimposed waves in the signal, i.e. arising from wave reflections of the structure components especially during the $45^{\circ}$ heading due to the maximised front face area.

As shown in Figure 7 the structure begins to roll in addition to the observed pitch behaviour for $0^{\circ}$ heading. The corresponding roll-RAO shows the same trend as pitch, being about $60 \%$ smaller for $\omega=$ $3 s^{-1}$ (see Figure 12).
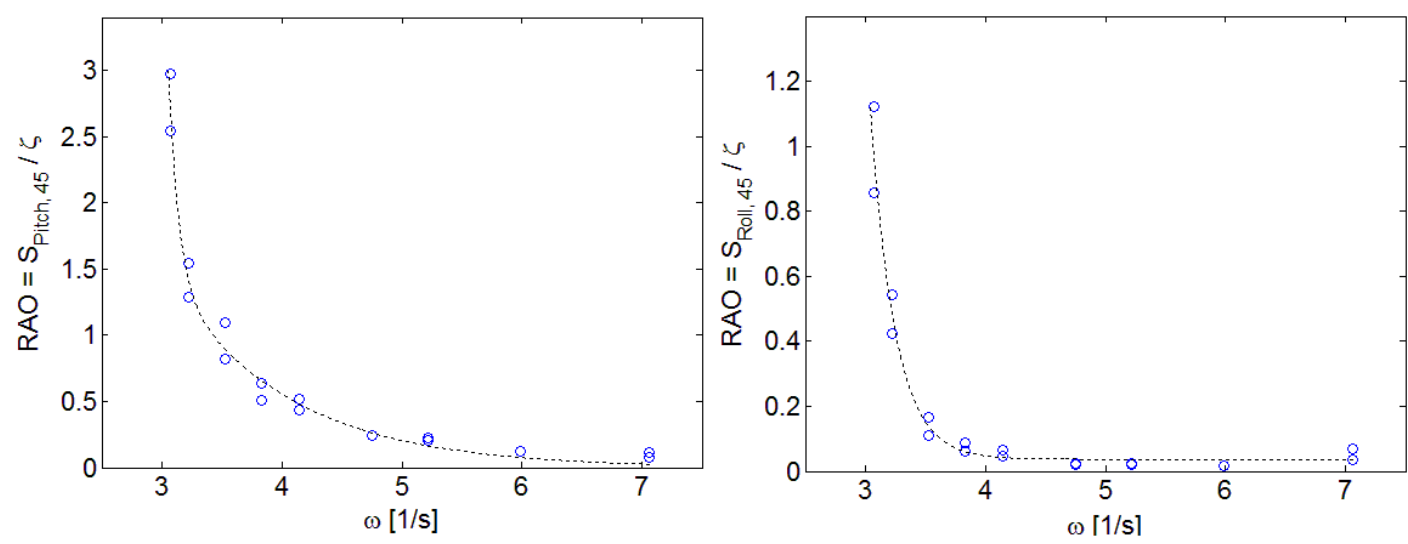

Figure 12. Pitch and Roll RAO for $45^{\circ}$ heading wave direction and wave periods of $0.90 \mathrm{~s}-2.09 \mathrm{~s}$

Transferring the analysed motion behaviour into nature scale the motion response is distinctive for about $8 \mathrm{~s} \geq T>10 \mathrm{~s}$ and $T>14 \mathrm{~s}$. However, the first mentioned section of wave periods is the most common range considering the data derived from FINO1. The probability of exceeding $T>8 \mathrm{~s}$ in the long time statistics of FINO1 is $43 \%$, which in turn implies that a save installation could be realized only in $57 \%$ of the time (see also Table 3).

\section{Conclusion}

The conducted experiments investigate the floating state for the installation of the HyConCast support structure for offshore wind turbines in water depths of 30 up to $50 \mathrm{~m}$. The successful usage of an infrared based motion tracking system is shown as well as the acceptable interference $(<3 \%)$ of the utilised soft mooring system for a model scale of 1:45.

The feasibility of the installation concept was evaluated with regard to the structure's response in regular waves. The frequency domain analysis of the test in $0^{\circ}$ and $45^{\circ}$ heading carried out RAO factors with their maxima close to the evaluated Eigenperiode of the structure. The critical heave motion RAO in $0^{\circ}$ heading was measured with 1.82 being slightly higher than in $45^{\circ}$ heading with a value of 1.7 . The critical rotational motion was pitch in both heading with $0^{\circ}$ generating a slightly higher response of $3 \% \mathrm{~cm}$. In addition, the roll motion in $45^{\circ}$ is induced due to slightly eccentric mass distribution and the small asymmetric momentum of the mooring lines. Compared to the pitch RAO, the maximum ratio for roll is $65 \%$ smaller. Due to limitations of the facility the RAO factor of the pitch Eigenperiode needs to be investigated through up following numerical tests.

At current state the chosen arrangement of the buoyancy tanks generates strong wave-structureinteractions for common waves $(T \geq 8 \mathrm{~s})$ in the projected area of the HyConCast structure.

Since the implementation of a large number of OWEP-foundations is required, further investigation is needed. For example the horizontal water-plane needs to be reduced to influence and modify the structure's response as well as the minimisation of the needed buoyancy and its overall rearrangement with focus on reducing the wetted surface. The results from the experiments are further used for the setup of numerical studies and optimisations.

\section{ACKNOWLEDGEMENTS}

The support of the research project "HyConCast - Hybrid substructure of high strength concrete and ductile iron castings for offshore wind turbines" (Funding Code FKZ 0325651A) by the German Federal Ministry for the Environment, Nature Conversation and Nuclear Safety is gratefully acknowledged. 


\section{NOMENCLATUR}

$\begin{array}{lll}\overline{B M} & \text { Contour Stability } & {[\mathrm{m}]} \\ d & \text { Diameter } & {[\mathrm{m}]} \\ \overline{G M} & \text { Stability Index } & {[\mathrm{m}]} \\ H & \text { Wave Height } & {[\mathrm{m}]} \\ H_{s} & \text { Significant Wave Height } & {[\mathrm{m}]} \\ h & \text { Height } & {[\mathrm{m}]} \\ k & \text { Radius of Gyration } & {[\mathrm{m}]} \\ m & \text { Mass } & {[\mathrm{t}][\mathrm{kg}]} \\ t & \text { Time } & {[\mathrm{s}]} \\ T & \text { Wave Period } & {[\mathrm{s}]} \\ T_{s} & \text { Significant Wave Period } & {[\mathrm{s}]} \\ \bar{V} & \text { Buoyancy } & {\left[\mathrm{m}^{3}\right]} \\ \bar{V}_{r e q} & \text { Buoyancy required } & {\left[\mathrm{m}^{3}\right]} \\ \bar{V}_{T=40} \mathrm{~m} & \text { Buoyancy at Experimental Draught } & {\left[\mathrm{m}^{3}\right]} \\ \rho_{w a t e r} & \text { Density of Water } & {\left[\mathrm{kg}^{3} \mathrm{~m}^{3}\right]} \\ \text { WEP } & \text { Wind energy plant } & \\ \text { OWEP } & \text { Offshore Wind energy plant } & \\ \text { RAO } & \text { Response amplitude operator } & \\ \text { FFT } & \text { Fast Fourier Transformation } & \end{array}$

\section{REFERENCES}

Bunnik, T and Buchner, B (2004): Experimental investigation of subsea structures during installation and the related wave loads, added mass and damping. In Proceedings of the $14^{\text {th }}$ International Offshore and Polar Engineering Conference, Toulon, France

Chakrabarti, S.K. (2005): Handbook of Offshore Engineering, Elsevier Ltd., Chapter 14

Cozijn, H., Uittenbogaard, R., Brake, E. (2005): Heave, Roll and Pitch Damping of a Deepwater CALM Buoy with a Skirt. In Proceedings of the $15^{\text {th }}$ International Offshore and Polar Engineering Conference, Seoul, South Korea, pp 388-395

IPCC Special Report SSREN (2011): Renewable Energy Sources and Climate Change Mitigation, Specia Report of the Intergovernmental Panel on Climate Change, SRREN, pp 870

Dhanak, M.R., Xiros, N.I. (2016): Springer Handbook of Ocean Engineering, Springer, Heidelberg 2016 pp 336-336

Honarvar, M.R., Moharam, D. P., Mohammad, R.B. (2008): A Physical and Numerical Modelling for Launching of Jackets (Case Study on Balal PLQ Platform), Journal of Offshore Mechanics and Arctic Engineering, August 2008, Vol.130/031004 pp1-8.

Kurian, V.J., Ng, C.Y., Liew, M.S. (2013): Effect of Short-crested Waves on the Dynamic Responses of Truss SPAR Platforms. In Proceedings of the $23^{\text {th }}$ International Offshore and Polar Engineering Conference, pp 900-906

Mansard, E., and Funke, E., (1980): The measurement of incident and reflected spectra using a least squares method. In Proceedings of the $17^{\text {th }}$ International Conference on Coastal Engineering, Vol. 1, Sydney, Australia, pp 54-172.

Nallayarasu, S. and Kumar, N.S. (2017): Experimental and numerical investigation on hydrodynamic response of buoy form spar under regular waves, Ships and Offshore Structures, 2017, Vol.12, No. $1,19-31$.

Noble, Denton and Associates Inc. (2013): Guidelines for Steel Jacket Transportation \& Installation, 0028/ND, pp 17-21

Sun, Huang, Wu (2012): The current state of offshore wind energy technology development, Elsevier journal, energy, pp 298-312 